\author{
Note
}

\title{
Association of fat mass and obesity-associated and retinitis pigmentosa guanosine triphosphatase (GTPase) regulator-interacting protein-1 like polymorphisms with body mass index in Chinese women
}

\author{
Boyu Chen ${ }^{1)}$, Zhiqiang $\mathrm{Li}^{1), 2), 3), 4)}$, Jianhua $\mathrm{Chen}^{1), 3), 5)}$, Jue $\mathrm{Ji}^{1)}$, Jingyi Shen ${ }^{1)}$, Yufeng $\mathrm{Xu}^{1)}$, Yingying Zhao ${ }^{1)}$, \\ Danping Liu ${ }^{1)}$, Yinhuan Shen ${ }^{1)}$, Weijie Zhang ${ }^{1)}$, Jiawei Shen ${ }^{1)}$, Yonggang Wang() and Yongyong Shi ${ }^{1), 2), 33,4), 5), 7)}$ \\ 1) Bio-X Institutes, Key Laboratory for the Genetics of Developmental and Neuropsychiatric Disorders (Ministry of Education), the \\ Collaborative Innovation Center for Brain Science, Shanghai Jiao Tong University, Shanghai 200030, China \\ 2) The Affiliated Hospital of Qingdao University \& The Biomedical Sciences Institute of Qingdao University (Qingdao Branch of \\ SJTU Bio-X Institutes), Qingdao University, Qingdao 266003, China \\ 3) Institute of Social Cognitive and Behavioral Sciences, Shanghai Jiao Tong University, Shanghai 200240, China \\ 4) Institute of Neuropsychiatric Science and Systems Biological Medicine, Shanghai Jiao Tong University, Shanghai 200042, China \\ 5) Shanghai Key Laboratory of Psychotic Disorders, Shanghai Mental Health Center, Shanghai Jiao Tong University School of \\ Medicine, Shanghai 200030, China \\ 6) Department of Neurology, School of Medicine, Renji Hospital, Shanghai Jiao Tong University, Shanghai 200127, China \\ 7) Changning Mental Health Center, Shanghai 200042, China
}

\begin{abstract}
Body mass index (BMI) is the most commonly used quantitative measure of adiposity. It is a kind of complex genetic diseases which are caused by multiple susceptibility genes. The first intron of fat mass and obesity-associated (FTO) has been widely discovered to be associated with BMI. Retinitis pigmentosa GTPase regulator-interacting protein-1 like $(R P G R I P 1 L)$ is located in the upstream region of FTO and has been proved to be linked with obesity through functional tests. We carried out a genetic association analysis to figure out the role of the FTO gene and the RPGRIPIL gene in BMI. A quantitative traits study with 6,102 Chinese female samples, adjusted for age, was performed during our project. Among the twelve SNPs, rs1421085, rs1558902, rs17817449, rs8050136, rs9939609, rs7202296, rs56137030, rs9930506 and rs 12149832 in the FTO gene were significantly associated with BMI after Bonferroni correction. Meanwhile, rs 9934800 in the RPGRIPIL gene showed significance with BMI before Bonferroni correction, but this association was eliminated after Bonferroni correction. Our results suggested that genetic variants in the FTO gene were strongly associated with BMI in Chinese women, which may serve as targets of pharmaceutical research and development concerning BMI. Meanwhile, we didn't found the significant association between RPGRIPIL and BMI in Chinese women.
\end{abstract}

Key words: Fat mass and obesity-associated, Retinitis pigmentosa GTPase regulator-interacting protein-1 like, Body mass index, Single-nucleotide polymorphism

OVERWEIGHT AND OBESITY have been a globally public health crisis, which increase the risk of diabetes,

Submitted Jan. 8, 2018; Accepted Mar. 22, 2018 as EJ17-0554 Released online in J-STAGE as advance publication Apr. 14, 2018 Correspondence to: Yongyong Shi, Bio-X Institutes, Shanghai Jiao Tong University, NO.1954 Huashan Road, Xuhui District, Shanghai 200030, China. E-mail: shiyongyong@gmail.com

Correspondence to: Yonggang Wang, Renji Hospital, Shanghai Jiao Tong University, NO.1630 Dongfang Road, Pudong District, Shanghai 200127, China. E-mail: w100yg@163.com heart disease, cancer and premature death $[1,2]$. At least 2.8 million adults die each year as a result of being overweight or obese. In addition, $44 \%$ of the diabetes, $23 \%$ of the ischemic heart disease and $7-41 \%$ of certain cancer burdens result from overweight and obesity (http:// www.who.int/bmi). In 2010, the prevalence of overweight and obesity among Chinese adults was $30.6 \%$ and $12.0 \%$, respectively [3]. There were 2.1 billion overweight and obese individuals all over the world in 2013 [4]. Trends of overweight and obesity in the Han Chinese population became worrisome during the past thirty 
years [5-8]. Scientists have involved themselves in the exploration of the molecular mechanisms of obesity and obesity-related diseases for a long time. Relevant studies showed that nearly $60 \%$ of obesity susceptibility was due to the difference between genotypes $[9,10]$.

Body mass index (BMI) is one of the most common used index for the diagnosis of obesity. The prevalence of hypertension, diabetes, dyslipidemia and clustering of risk factors is related with the increasing levels of BMI [11]. BMI has a strong heritability ranging from $40 \%$ to $80 \%$, including several genes which express in the hypothalamus and play key roles in the regulation of appetite $[12,13]$. A meta-analysis showed that both the lower and higher level of BMI contributed to the risk of all-cause mortality in Asian adults [14]. Genome-wide association studies (GWAS) have so far identified 32 loci strongly associated with BMI [12, 15-18].

The fat mass and obesity-associated (FTO) gene was firstly reported to be associated with obesity $[16,19,20]$. FTO is located on the chromosome $16 \mathrm{q} 12.2$ of the human genome and expresses in almost all tissues [21]. It spans more than $4,000 \mathrm{~kb}$ of DNA and consists of 9 exons. Previous studies proved that FTO played an important role in the nucleic acid demethylation, balance of energy homeostasis and regulation of body fat masses with the help of lipolysis [22, 23]. Its influence on adiposity was supposed to work out through the way of affecting appetite [24]. Take the example of SNP rs9939609, which was mostly widely studied all over the world, adults carried A allele at rs 9939609 were substantially obese in Europe (OR 1.67, 95\% CI 1.47-1.89, $p=$ $1 \times 10^{-14}$ ) [16], Denmark (OR 1.27, 95\% CI 1.20-1.34, $p$ $\left.=2 \times 10^{-16}\right)$ [25], North India (OR 1.3, 95\% CI 1.1-1.7, $p=0.012$ ) [26] and Japan (OR 1.38, 95\% CI 1.20-1.59, $p=1.2 \times 10^{-5}$ ) [27]. Meanwhile, rs9939609 was associated with BMI in Chinese girls aged 12 18 years $(\beta=$ $1.07, p=0.008)$ [28], Korean population $(\beta=0.335, p=$ $\left.1.5 \times 10^{-7}\right)[29]$ and Sorbian population $(\beta=0.021, p=$ 0.0087 ) [30], but this SNP was not significantly associated with BMI in Japanese population (AA $23.22 \pm 3.14$ vs. AT $22.79 \pm 3.25 v s$. TT $22.58 \pm 3.13, p=0.063$ ) [27].

Retinitis pigmentosa GTPase regulator-interacting protein-1 like (RPGRIPIL) is a ciliary gene located in close proximity to the transcriptional start site of FTO and is a transition zone structural component of the primary cilium which is related to human energy homeostasis [31, 32]. RPGRIPIL is located on the chromosome $16 \mathrm{q} 12.2$ of the human genome and lies in close proximity $5^{\prime}$ of and in the opposite direction as FTO. It spans more than $100 \mathrm{~kb}$ of DNA and consists of 27 exons [33]. One RT-PCR analysis detected that RPGRIPIL was strongly expressed in adult human testis and kidney [34]. Both RPGRIPIL and FTO belonged to consecutive genes, which were detected on the missing $1.6-\mathrm{Mb}$ chromosome segment in fused-toe mice [35]. RPGRIPIL is a component of the basal body of the cilium [36, 37] and might play an important role in the pathway of human energy [38].

We aimed to figure out whether the FTO gene and RPGRIPIL gene play significant roles in BMI in Chinese female population. Both of them locate in the same pathway and the mechanism of the association among these two genes and obesity remains unknown, so we hypothesized that this pathway composed of FTO and RPGRIP1L might have some effects on obesity and BMI.

\section{Materials and Methods}

We performed the study in 6,102 Chinese female samples totally. Average age, BMI, waist circumference, height and body weight of participants is 19.7 years (s.d. $=2.9), 20.4 \mathrm{~kg} / \mathrm{m}^{2}($ s.d. $=2.4), 70.0 \mathrm{~cm}($ s.d. $=6.7), 161.6$ $\mathrm{cm}(s . d .=5.5)$ and $53.2 \mathrm{~kg}(s . d .=7.1)$ respectively. Subjects wore light clothing during the measurement, without shoes. BMI is calculated by dividing weight in kilogram's by height in meters squared. We run the tape measure around the waist with three centimeters above the belly button to get the data of waist circumference. Statistical power was calculated by G-power software (http://gpower.hhu.de). A normal distribution of our data is shown in Fig. 1 using the normality test and distribution curve.

The association between the FTO gene and BMI has been widely reported. Based on previous reports [39-43], we selected nine variants rs1421085, rs 1558902 , rs17817449, rs8050136, rs9939609, rs7202296, rs56137030, rs9930506 and rs12149832 for analysis and they were distributed along a $45-\mathrm{kb}$ stretch of intron 1 of FTO. Tag SNPs selection of the RPGRIPIL gene was performed with the Haploview software (Broad Institute; www.broadinstitute.org), with $r^{2} \geq 0.8$ and MAF $\geq 0.05$ $[44,45]$. Three SNPs rs9934800, rs5005161 and rs35089292 were selected according to the results. The relationship between tag SNPs and the FTO gene and the RPGRIPIL gene is shown in Fig. 2. In accordance with the study protocol, the Swab DNA Kit (FineGene) was used to extract genomic DNA from saliva samples. We used $1 \mu \mathrm{L}$ DNA solution (approximately $20 \mathrm{ng} / \mu \mathrm{L}$ ) for 


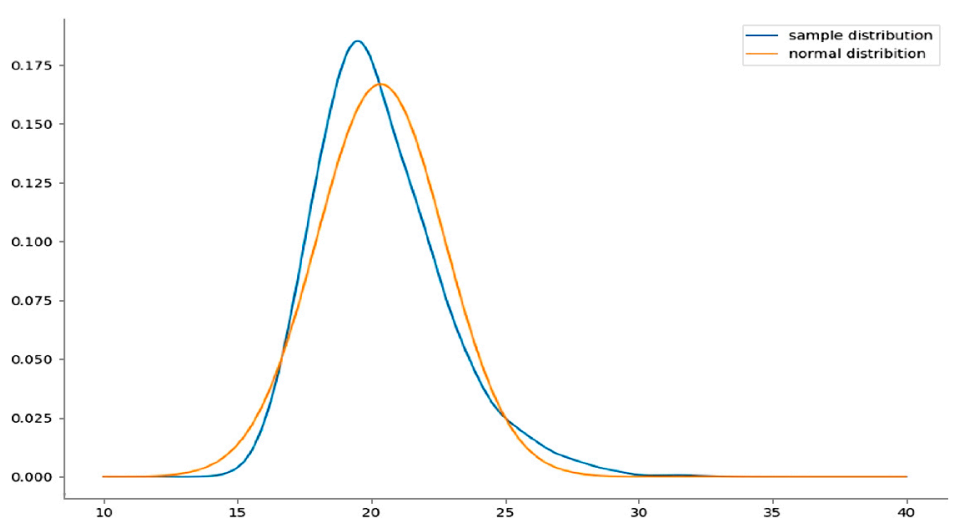

Fig. 1 The distribution of the BMI of samples, plotted by BMI on the horizontal axis and probability density on the vertical.

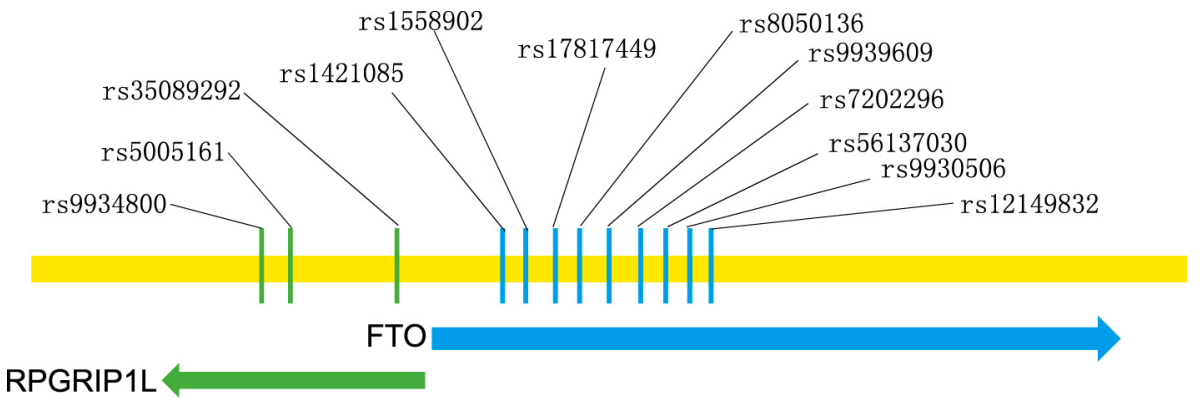

\section{Chromosome16q12.2}

Fig. 2 Relationship between tag SNPs and the FTO gene and the RPGRIPIL gene.

genotyping. Genotyping was conducted using Affymetrix Axiom ${ }^{\circledR}$ Genome-Wide CHB1/2 Array, as described previously [46].

A linear regression model with BMI as a continuous trait, adjusted for age, was applied to investigate the influence of FTO polymorphisms on BMI. Association analysis of SNPs were performed with the SHEsis software [47, 48], including Hardy-Weinberg equilibrium, allelic frequency calculation, pairwise linkage disequilibrium and haplotype analysis. All tests were two-tailed and $p<0.05$ was considered significant. Correction for multiple-hypothesis testing was adopted with the Bonferroni correction.

\section{Results}

Power of statistics equaled 1 finally, indicating strong statistical power. we selected 74 pairs of random repeated samples for genotyping duplicate and the concordance rates of genotyping was 0.996 . The average call rate of all SNPs was 0.997, and no deviation from Hardy-
Weinberg equilibrium was found ( $p \geq 0.05$ ). Information of all SNPs in our study is shown in Table 1. Detailed association analysis results of all testing sites are listed in Table 2. It shows the results for the nine polymorphic SNPs, rs1421085, rs1558902, rs17817449, rs8050136, rs9939609, rs7202296, rs56137030, rs9930506 and rs12149832 in the FTO gene were significantly associated with BMI after Bonferroni correction, during which rs8050136 showed the strongest association with BMI. Meanwhile, rs9934800 in the RPGRIPIL gene showed significance with BMI before Bonferroni correction, but this association was eliminated after Bonferroni correction.

The pairwise linkage disequilibrium among the investigated SNPs in the FTO gene and the RPGRIPIL gene is shown in Fig. 3. $R^{2}$ values of nine FTO variants were lager than 0.33 and they were categorized in the same haplotype block. Haplotype analysis of the block, rs1421085-rs1558902-rs17817449-rs8050136-rs9939609rs7202296-rs56137030-rs9930506-rs12149832, is shown in Table 3. 
Table 1 Information of twelve SNPs in FTO and RPGRIPIL gene

\begin{tabular}{cccccc}
\hline SNP ID & Position & Function & Polymorphism & Call Rate & H-W $p$ value \\
\hline rs9934800 & Chr16:53654582 & intron & C/T & 1.000 & 0.762 \\
rs5005161 & Chr16:53664764 & intron & $\mathrm{C} / \mathrm{T}$ & 0.999 & 0.483 \\
\hline rs35089292 & Chr16:53692910 & intron & $\mathrm{C} / \mathrm{A}$ & 0.995 & 0.361 \\
\hline rs1421085 & Chr16:53767042 & intron & $\mathrm{C} / \mathrm{T}$ & 1.000 & 0.789 \\
rs1558902 & Chr16:53769662 & intron & $\mathrm{A} / \mathrm{T}$ & 0.998 & 0.644 \\
rs17817449 & Chr16:53779455 & intron & $\mathrm{G} / \mathrm{T}$ & 0.996 & 0.438 \\
rs8050136 & Chr16:53782363 & intron & $\mathrm{A} / \mathrm{C}$ & 1.000 & 0.744 \\
rs9939609 & Chr16:53786615 & intron & $\mathrm{A} / \mathrm{T}$ & 0.999 & 0.627 \\
rs7202296 & Chr16:53787778 & intron & $\mathrm{A} / \mathrm{G}$ & 0.996 & 0.457 \\
rs56137030 & Chr16:53791993 & intron & $\mathrm{A} / \mathrm{G}$ & 0.998 & 0.394 \\
rs9930506 & Chr16:53796553 & intron & $\mathrm{A} / \mathrm{G}$ & 1.000 & 0.926 \\
\hline rs12149832 & Chr16:53808996 & intron & $\mathrm{A} / \mathrm{G}$ & 0.990 & 0.221 \\
\hline
\end{tabular}

Table 2 Linear regression analysis of SNPs, adjusted for age

\begin{tabular}{|c|c|c|c|c|c|c|}
\hline Locus & SNP & \multicolumn{2}{|c|}{ Allele Frequency } & Beta & $p$ & Bonferroni $p$ \\
\hline & rs9934800 & C $1648(0.135)$ & Т $10550(0.865)$ & 0.144 & 0.021 & 0.252 \\
\hline \multirow[t]{6}{*}{ PRGRIPIL } & rs5005161 & C $5125(0.420)$ & Т $7065(0.580)$ & -0.003 & 0.939 & 1 \\
\hline & rs35089292 & C $1470(0.121)$ & A $10676(0.879)$ & -0.06 & 0.362 & 1 \\
\hline & rs 1421085 & C $1644(0.135)$ & Т $10560(0.865)$ & 0.334 & $1.16 \times 10^{-7}$ & $1.39 \times 10^{-6}$ \\
\hline & rs 1558902 & A $1630(0.134)$ & Т $10548(0.866)$ & 0.332 & $1.49 \times 10^{-7}$ & $1.79 \times 10^{-6}$ \\
\hline & rs17817449 & G $1614(0.133)$ & Т $10538(0.867)$ & 0.329 & $2.03 \times 10^{-7}$ & $2.44 \times 10^{-6}$ \\
\hline & rs 8050136 & A $1646(0.135)$ & C 10558 (0.865) & 0.334 & $1.08 \times 10^{-7}$ & $1.30 \times 10^{-6}$ \\
\hline \multirow[t]{5}{*}{ FTO } & rs9939609 & A $1619(0.133)$ & Т $10569(0.867)$ & 0.326 & $2.66 \times 10^{-7}$ & $3.19 \times 10^{-6}$ \\
\hline & rs7202296 & G $1606(0.132)$ & A $10554(0.868)$ & 0.316 & $6.56 \times 10^{-7}$ & $7.87 \times 10^{-6}$ \\
\hline & rs56137030 & A $1608(0.132)$ & G $10572(0.868)$ & 0.318 & $5.10 \times 10^{-7}$ & $6.12 \times 10^{-6}$ \\
\hline & rs9930506 & G $2289(0.188)$ & A 9915 (0.812) & 0.208 & $1.73 \times 10^{-4}$ & $2.08 \times 10^{-3}$ \\
\hline & rs12149832 & A $1636(0.135)$ & G $10440(0.865)$ & 0.296 & $2.92 \times 10^{-6}$ & $3.50 \times 10^{-5}$ \\
\hline
\end{tabular}

Bold font denotes significant $p$-values $(<0.05)$ after Bonferroni correction.

\section{Discussion}

In this study, we examined the associations of SNPs within the FTO gene and the RPGRIPIL gene with BMI in Chinese women.

Although the FTO region harbors the strongest genetic association with BMI, the mechanistic basis remains unclear. Previous reports have widely studied the association between the FTO gene and BMI in various populations $[16,25-30]$. We therefore postulated that this association would still exist in Chinese women and selected nine SNPs for further replication experiments during these reports. Our study confirmed that nine SNPs in the FTO locus, rs1421085, rs1558902, rs17817449, rs8050136, rs9939609, rs7202296, rs56137030, rs9930506 and rs12149832, were associated with BMI in a quantitative traits study with large sample sizes of a Han Chinese origin, which may serve as targets of pharmaceutical research and development concerning BMI.

The FTO protein is part of the AlkB family of non-home 


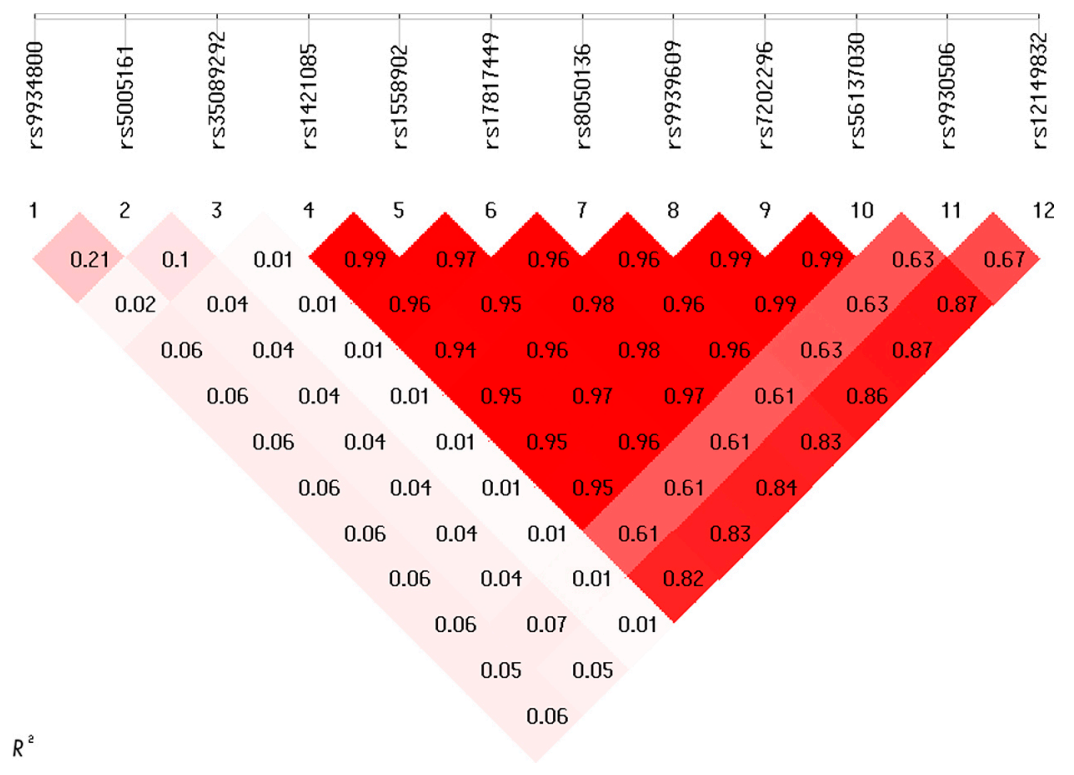

Fig. 3 The pairwise linkage disequilibrium among the investigated SNPs in the FTO gene and the RPGRIPIL gene. The pairwise LD $r^{2}$ values were illustrated in the matrices. The deep color indicated relatively strong linkage disequilibrium, and vice versa.

Fe (II)/dioxygenases, which belongs to the Escherichia coli AlkB and human ABH enzyme family [49, 50]. A meta-analysis indicated that the connection between FTO SNPs and BMI could be modified by physical activity (PA). It showed that physically active adults with risk allele homozygous SNP of rs9939609 reduced the odds of obesity by $27 \%$ [51]. The interaction between the rs1421085 and PA in six ethnic groups was also identified in another study [52], which included East Asian, South Asian, African, Native American, Latin American and European. Several studies explored the link between FTO SNPs and food intake to figure out the mechanisms for variants in FTO and the risk of adiposity. The BMIincreasing allele of rs1421085 was found to be associated with higher protein intake [53]. The risk allele of rs8050136 was found to be related to the percentage of calories from fat and negatively related to the percentage of energy from carbohydrates [54]. The risk allele of rs9939609 was also verified to decrease fiber intake and increase protein intake [55]. One breakthrough found that the rs $1421085 \mathrm{~T}-\mathrm{C}$ alteration disrupted a conserved motif for the regulatory gene $A R I D 5 B$, causing derepression of a potent preadipocyte enhancer that ultimately resulted in a cell-autonomous developmental shift from energy-dissipating beige adipocytes to energy-storing white adipocytes, with a 5-fold reduction in mitochondrial thermogenesis and an increase in lipid storage [56]. It meant that the FTO SNP rs1421085 represented the
Table 3 Haplotype analysis of FTO gene

\begin{tabular}{|c|c|c|c|c|}
\hline Haplotype & Beta & SE & $p$ & Bonferroni $p$ \\
\hline TTTCTAGAG & -0.226 & 0.055 & $4.30 \times 10^{-5}$ & $1.29 \times 10^{-4}$ \\
\hline CAGAAGAGA & 0.341 & 0.065 & $1.98 \times 10^{-7}$ & $5.94 \times 10^{-7}$ \\
\hline TTTCTAGGG & -0.103 & 0.103 & 0.315 & 0.945 \\
\hline
\end{tabular}

Haplotypes with frequency $<0.03$ were ignored.

Bold font denotes significant $p$-values $(<0.05)$ after Bonferroni correction.

causal variant that disrupted a pathway for adipocyte thermogenesis, providing a mechanistic basis for the genetic association between FTO and BMI.

Previous studies confirmed the role RPGRIPIL gene played in obesity and indicated that RPGRIPIL linked to obesity-associated variants in the $F T O$ gene functionally [57-59]. We therefore supposed that RPGRIPIL might also connect with BMI. To our knowledge, the association analysis between the RPGRIPIL gene and BMI has rarely been noted. We found that rs9934800 of RPGRIP1L showed significance with BMI before Bonferroni correction. However, the association was too weak and it was eliminated after Bonferroni correction. The other two SNPs in the RPGRIPIL locus, rs5005161 and rs35089292, weren't found association with BMI.

Some researchers focused on the transcription factor the cut-like homeobox 1 (CUX1), which displaced acti- 
vators and recruited histone deacetylase 1 to transcribe repressor. The obesity-protective allele of rs8050136 in FTO advanced the DNA-binding of CUX1 isoform P110, which catalyzed the expression of FTO and RPGRIPIL $[18,19]$. Reversely, the obesity-risk allele of rs 8050136 tended to act on CUX1 isoform P200, which was a transcriptional repressor of FTO [19]. This study showed that $70 \%$ reduction in cutl1 mediated by siRNA contributed to $90 \%$ decrease in FTO expression and 65\% decrease in RPGRIP1L expression. Both of them could be identified as cux 1 protein binding sites, so it seemed that FTO variation changed RPGRIPIL expression indirectly. Hemizygous RPGRIPIL mice with function reduced, were used for further research to explore the relationship between RPGRIPIL and obesity. Results indicated that the RPGRIPIL $L^{+/-}$mice consumed more food and increased higher weight than normal ones. Deficiency of leptin receptor signaling in RPGRIPIL $L^{+/-}$ mice was identified in subsequent studies and RPGRIPIL was speculated to deliver the formation of leptin receptor clustering.

Haplotype association analysis identified a protective haplotype in FTO locus, T-T-T-C-T-A-G-A-G, carrying the major allele of nine SNPs in this block (rs1421085rs1558902-rs17817449-rs8050136-rs9939609-rs7202296rs56137030-rs9930506-rs12149832) with BMI. Additionally, we found a risk haplotype C-A-G-A-A-G-A-G-A carrying the minor allele of these SNPs with BMI. The results of haplotype association verified the analysis of single polymorphism sites.

In conclusion, our main finding was a significant association between FTO and BMI, although not between RPGRIP1L and BMI, in Chinese women. Both of them locate in the same pathway and RPGRIPIL lies upstream of FTO. If this pathway is connected with obesity or BMI, knocking out RPGRIP1L may disorder its function and lead to the fat phenotype of mice. In other words, we speculated it's FTO, not RPGRIPIL, contributing to obesity. Despite our sample size was relatively large and we achieved association significance of common variants, further evidence from functional experiments was needed to support our findings and to show the role of
FTO, RPGRIPIL or related pathways in the mechanism of BMI.

\section{Acknowledgements}

We thank all the participants who contributed to this project. Y.S. and Y.W. conceived, designed and supervised the study, and obtained financial support; B.C., J.J., J.S., Y.X., Y.Z., D.L., Y.S. and W.Z. participated in sample collection and phenotyping; B.C., J.C., J.J., J.S., Y.X., Y.Z., D.L., Y.S. and W.Z. performed sample processing and involved in data management; J.C., Z.L. and J.S. conducted bioinformatics/statistical analysis; B.C. interpreted the data and drafted the manuscript. All authors read and approved the final manuscript.

\section{Disclosure}

This work was supported by the 973 Program (2015CB559100), the National Key R\&D Program of China (2016YFC0903402), the Natural Science Foundation of China (31325014, 81421061, 81130022, 81701321,31770800 and 81571329), the Program of Shanghai Subject Chief Scientist (15XD1502200), the National Program for Support of Top-Notch Young Professionals to Y.S., the 'Shu Guang' project supported by the Shanghai Municipal Education Commission and Shanghai Education Development Foundation (12SG17), Shanghai Municipal Education Commission-Gaofeng Clinical Medicine Grant Support (20161414), the China Postdoctoral Science Foundation (2016M590615), the Shandong Postdoctoral Innovation Foundation (201601015), the Qingdao Postdoctoral Application Research Project (2016048).

All participants signed written informed consent. Our study was approval of the Ethics Committee of Human Genetic Resources in Bio-X Institutes at Shanghai Jiao Tong University and corresponded to the 'Guidance of the Ministry of Science and Technology for the Review and Approval of Human Genetic Resources'.

The authors declare no competing financial interests.

\section{References}

1. Abelson P, Kennedy D (2004) The obesity epidemic. Science 304: 1413.

2. Haslam DW, James WP (2005) Obesity. Lancet 366:
1197-1209.

3. Li XY, Jiang Y, Hu N, Li YC, Zhang M, et al. (2012) Prevalence and characteristic of overweight and obesity 
among adults in China, 2010. Zhonghua Yu Fang Yi Xue Za Zhi 46: 683-686 (In Chinese).

4. Ng M, Fleming T, Robinson M, Thomson B, Graetz N, et al. (2014) Global, regional, and national prevalence of overweight and obesity in children and adults during 1980-2013: a systematic analysis for the Global Burden of Disease Study 2013. Lancet 384: 766-781.

5. Wildman RP, Gu D, Muntner P, Wu X, Reynolds K, et al. (2008) Trends in overweight and obesity in Chinese adults: between 1991 and 1999-2000. Obesity (Silver Spring) 16: 1448-1453.

6. Xi B, Liang Y, He T, Reilly KH, Hu Y, et al. (2012) Secular trends in the prevalence of general and abdominal obesity among Chinese adults, 1993-2009. Obes Rev 13: 287-296.

7. Wang $\mathrm{W}, \mathrm{Wu} \mathrm{ZS}$, Zhao $\mathrm{D}, \mathrm{Wu}$ GX, Wang WH, et al. (2003) The trends of body mass index and overweight in population aged 25-64 in Beijing during 1984-1999. Zhonghua Liu Xing Bing Xue Za Zhi 24: 272-275 (In Chinese).

8. Li F, Fan JG, Cai XB (2007) Study on the prevailing trend of overweight and obesity in Shanghai Bao-Steel Company based population from 1995 to 2002. Zhonghua Yu Fang Yi Xue Za Zhi 41: 38-41 (In Chinese).

9. Elks CE, den Hoed M, Zhao JH, Sharp SJ, Wareham NJ, et al. (2012) Variability in the heritability of body mass index: a systematic review and meta-regression. Front Endocrinol (Lausanne) 3: 29.

10. Maes HH, Neale MC, Eaves LJ (1997) Genetic and environmental factors in relative body weight and human adiposity. Behav Genet 27: 325-351.

11. Zhou BF (2002) Predictive values of body mass index and waist circumference for risk factors of certain related diseases in Chinese adults - study on optimal cut-off points of body mass index and waist circumference in Chinese adults. Biomed Environ Sci 15: 83-96.

12. Speliotes EK, Willer CJ, Berndt SI, Monda KL, Thorleifsson G, et al. (2010) Association analyses of 249,796 individuals reveal 18 new loci associated with body mass index. Nat Genet 42: 937-948.

13. Locke AE, Kahali B, Berndt SI, Justice AE, Pers TH, et al. (2015) Genetic studies of body mass index yield new insights for obesity biology. Nature 518: 197-206.

14. Wang YQ, Ye D, Li YJ, Chen K (2015) Body mass index and all-cause mortality in Asian adults: a meta-analysis. Zhejiang Da Xue Xue Bao Yi Xue Ban 44: 189-196 (In Chinese).

15. Willer CJ, Speliotes EK, Loos RJ, Li S, Lindgren CM, et al. (2009) Six new loci associated with body mass index highlight a neuronal influence on body weight regulation. Nat Genet 41: 25-34.

16. Frayling TM, Timpson NJ, Weedon MN, Zeggini E, Freathy RM, et al. (2007) A common variant in the FTO gene is associated with body mass index and predisposes to childhood and adult obesity. Science 316: 889-894.

17. Loos RJ, Lindgren CM, Li S, Wheeler E, Zhao JH, et al. (2008) Common variants near MC4R are associated with fat mass, weight and risk of obesity. Nat Genet 40: 768775 .

18. Thorleifsson G, Walters GB, Gudbjartsson DF, Steinthorsdottir V, Sulem P, et al. (2009) Genome-wide association yields new sequence variants at seven loci that associate with measures of obesity. Nat Genet 41: 18-24.

19. Hinney A, Nguyen TT, Scherag A, Friedel S, Bronner G, et al. (2007) Genome wide association (GWA) study for early onset extreme obesity supports the role of fat mass and obesity associated gene (FTO) variants. PLoS One 2: e1361.

20. Scuteri A, Sanna S, Chen WM, Uda M, Albai G, et al. (2007) Genome-wide association scan shows genetic variants in the FTO gene are associated with obesity-related traits. PLoS Genet 3: e115.

21. Hubacek JA, Stanek V, Gebauerova M, Pilipcincova A, Dlouha D, et al. (2010) A FTO variant and risk of acute coronary syndrome. Clin Chim Acta 411: 1069-1072.

22. Dina C, Meyre D, Gallina S, Durand E, Korner A, et al. (2007) Variation in FTO contributes to childhood obesity and severe adult obesity. Nat Genet 39: 724-726.

23. Razquin C, Marti A, Martinez JA (2011) Evidences on three relevant obesogenes: MC4R, FTO and PPAR $\gamma$. Approaches for personalized nutrition. Mol Nutr Food Res 55: 136-149.

24. den Hoed M, Westerterp-Plantenga MS, Bouwman FG, Mariman EC, Westerterp KR (2009) Postprandial responses in hunger and satiety are associated with the rs9939609 single nucleotide polymorphism in FTO. Am J Clin Nutr 90: 1426-1432.

25. Andreasen $\mathrm{CH}$, Stender-Petersen KL, Mogensen MS, Torekov SS, Wegner L, et al. (2008) Low physical activity accentuates the effect of the FTO rs9939609 polymorphism on body fat accumulation. Diabetes 57: 95-101.

26. Prakash J, Mittal B, Srivastava A, Awasthi S, Srivastava N (2016) Association of FTO rs9939609 SNP with obesity and obesity-associated phenotypes in a north Indian population. Oman Med J 31: 99-106.

27. Hotta K, Nakata Y, Matsuo T, Kamohara S, Kotani K, et al. (2008) Variations in the FTO gene are associated with severe obesity in the Japanese. J Hum Genet 53: 546-553.

28. Zhang M, Zhao X, Cheng H, Wang L, Xi B, et al. (2014) Age- and sex-dependent association between FTO rs9939609 and obesity-related traits in Chinese children and adolescents. PLoS One 9: e97545.

29. Cho YS, Go MJ, Kim YJ, Heo JY, Oh JH, et al. (2009) A large-scale genome-wide association study of Asian populations uncovers genetic factors influencing eight quantitative traits. Nat Genet 41: 527-534. 
30. Tönjes A, Zeggini E, Kovacs P, Böttcher Y, Schleinitz D, et al. (2010) Association of FTO variants with BMI and fat mass in the self-contained population of Sorbs in Germany. Eur J Hum Genet 18: 104-110.

31. Liu L, Zhang M, Xia Z, Xu P, Chen L, et al. (2011) Caenorhabditis elegans ciliary protein NPHP-8, the homologue of human RPGRIPIL, is required for ciliogenesis and chemosensation. Biochem Biophys Res Commun 410: 626-631.

32. Williams CL, Li C, Kida $\mathrm{K}$, Inglis $\mathrm{PN}$, Mohan $\mathrm{S}$, et al. (2011) MKS and NPHP modules cooperate to establish basal body/transition zone membrane associations and ciliary gate function during ciliogenesis. J Cell Biol 192: 1023-1041.

33. Delous M, Baala L, Salomon R, Laclef C, Vierkotten J, et al. (2007) The ciliary gene RPGRIPIL is mutated in cerebello-oculo-renal syndrome (Joubert syndrome type B) and Meckel syndrome. Nat Genet 39: 875-881.

34. Arts HH, Doherty D, van Beersum SE, Parisi MA, Letteboer SJ, et al. (2007) Mutations in the gene encoding the basal body protein RPGRIPIL, a nephrocystin-4 interactor, cause Joubert syndrome. Nat Genet 39: 882-888.

35. Peters T, Ausmeier K, Ruther U (1999) Cloning of Fatso (Fto), a novel gene deleted by the Fused toes (Ft) mouse mutation. Mamm Genome 10: 983-986.

36. Vierkotten J, Dildrop R, Peters T, Wang B, Ruther U (2007) Ftm is a novel basal body protein of cilia involved in Shh signalling. Development 134: 2569-2577.

37. Khanna H, Davis EE, Murga-Zamalloa CA, EstradaCuzcano A, Lopez I, et al. (2009) A common allele in RPGRIPIL is a modifier of retinal degeneration in ciliopathies. Nat Genet 41: 739-745.

38. Baker K, Beales PL (2009) Making sense of cilia in disease: the human ciliopathies. Am J Med Genet C Semin Med Genet 151C: 281-295.

39. Gonzalez JR, Gonzalez-Carpio M, Hernandez-Saez R, Serrano Vargas V, Torres Hidalgo G, et al. (2012) FTO risk haplotype among early onset and severe obesity cases in a population of western Spain. Obesity (Silver Spring) 20: 909-915.

40. Albuquerque D, Nobrega C, Manco L (2013) Association of FTO polymorphisms with obesity and obesity-related outcomes in Portuguese children. PLoS One 8: e54370.

41. Zermeno-Rivera JJ, Astocondor-Perez JP, Valle Y, Padilla-Gutierrez JR, Orozco-Castellanos R, et al. (2014) Association of the FTO gene SNP rs17817449 with body fat distribution in Mexican women. Genet Mol Res 13: 8561-8567.

42. Prakash J, Srivastava N, Awasthi S, Agarwal CG, Natu SM, et al. (2011) Association of FTO rs17817449 SNP with obesity and associated physiological parameters in a north Indian population. Ann Hum Biol 38: 760-763.

43. Chuenta W, Phonrat B, Tungtrongchitr A, Limwongse C,
Chongviriyaphan N, et al. (2015) Common variations in the FTO gene and obesity in Thais: a family-based study. Gene 558: 75-81.

44. de Bakker PI, Burtt NP, Graham RR, Guiducci C, Yelensky R, et al. (2006) Transferability of tag SNPs in genetic association studies in multiple populations. Nat Genet 38: 1298-1303.

45. de Bakker PI, Yelensky R, Pe'er I, Gabriel SB, Daly MJ, et al. (2005) Efficiency and power in genetic association studies. Nat Genet 37: 1217-1223.

46. Li Z, Chen J, Zhao Y, Wang Y, Xu J, et al. (2017) Common variants in ZMIZ1 and near NGF confer risk for primary dysmenorrhoea. Nat Commun 8: 14900.

47. Shi YY, He L (2005) SHEsis, a powerful software platform for analyses of linkage disequilibrium, haplotype construction, and genetic association at polymorphism loci. Cell Res 15: 97-98.

48. Li Z, Zhang Z, He Z, Tang W, Li T, et al. (2009) A partition-ligation-combination-subdivision EM algorithm for haplotype inference with multiallelic markers: update of the SHEsis (http: //analysis.bio-x.cn/). Cell Res 19: 519-523.

49. Bleijlevens B, Shivarattan T, van den Boom KS, de Haan $A$, van der Zwan G, et al. (2012) Changes in protein dynamics of the DNA repair dioxygenase AlkB upon binding of $\mathrm{Fe}^{2+}$ and 2-oxoglutarate. Biochemistry 51: 3334-3341.

50. Gerken T, Girard CA, Tung YC, Webby CJ, Saudek V, et al. (2007) The obesity-associated FTO gene encodes a 2oxoglutarate-dependent nucleic acid demethylase. Science 318: 1469-1472.

51. Kilpelainen TO, Qi L, Brage S, Sharp SJ, Sonestedt E, et al. (2011) Physical activity attenuates the influence of FTO variants on obesity risk: a meta-analysis of 218,166 adults and 19,268 children. PLoS Med 8: e100116.

52. Reddon H, Gerstein HC, Engert JC, Mohan V, Bosch J, et al. (2016) Physical activity and genetic predisposition to obesity in a multiethnic longitudinal study. Sci Rep 6: 18672 .

53. Tanaka T, Ngwa JS, van Rooij FJ, Zillikens MC, Wojczynski MK, et al. (2013) Genome-wide metaanalysis of observational studies shows common genetic variants associated with macronutrient intake. Am J Clin Nutr 97: 1395-1402.

54. Park SL, Cheng I, Pendergrass SA, Kucharska-Newton AM, Lim U, et al. (2013) Association of the FTO obesity risk variant rs8050136 with percentage of energy intake from fat in multiple racial/ethnic populations: the PAGE study. Am J Epidemiol 178: 780-790.

55. McCaffery JM, Papandonatos GD, Peter I, Huggins GS, Raynor HA, et al. (2012) Obesity susceptibility loci and dietary intake in the Look AHEAD Trial. Am J Clin Nutr 95: 1477-1486. 
56. Claussnitzer M, Dankel SN, Kim KH, Quon G, Meuleman $\mathrm{W}$, et al. (2015) FTO obesity variant circuitry and adipocyte browning in humans. N Engl J Med 373: 895-907.

57. Stratigopoulos G, Burnett LC, Rausch R, Gill R, Penn DB, et al. (2016) Hypomorphism of FTO and RPGRIP1L causes obesity in mice. J Clin Invest 126: 1897-1910.

58. Stratigopoulos G, Martin Carli JF, O'Day DR, Wang L, Leduc CA, et al. (2014) Hypomorphism for RPGRIPIL, a ciliary gene vicinal to the FTO locus, causes increased adiposity in mice. Cell Metab 19: 767-779.

59. Stratigopoulos G, LeDuc CA, Cremona ML, Chung WK, Leibel RL (2011) Cut-like homeobox 1 (CUX1) regulates expression of the fat mass and obesity-associated and retinitis pigmentosa GTPase regulator-interacting protein-1like $(R P G R I P 1 L)$ genes and coordinates leptin receptor signaling. J Biol Chem 286: 2155-2170. 